\section{Autoantibodies to IA-2 not detected in NOD mice or BB rats}

Dear Sir,

IA-2 mRNA is expressed in both human pancreatic islets and brain [1]. It encodes a 979 amino acid protein that is a major autoantigen in insulin-dependent diabetes mellitus (IDDM) $[2,3]$. Up to $70 \%$ of IDDM patients have antibodies to IA-2 [4]. In clinically non-diabetic subjects, the appearance of autoantibodies to IA-2 is highly predictive in identifying individuals at high risk of subsequently developing clinical disease [5].

The diabetic syndrome in NOD mice and BB rats has features which both resemble and differ from those of IDDM in humans [6]. The present investigation was initiated to see whether IA-2 was also an autoantigen in these animal models.

Mouse IA-2 is expressed in both mouse pancreatic islets and brain [7]. It is also 979 amino acids in length. Its intracellular domain is $98.4 \%$ similar to the intracellular domain of human IA-2, and its extracellular domain is $87.2 \%$ similar to the extracellular domain of human IA-2. The intracellular and extracellular domains of rat IA-2 [8] are $99 \%$ and $87 \%$ similar, respectively, to the intracellular and extracellular domains of human IA-2. Sera from normal, prediabetic and diabetic mice and rats were collected and tested for autoantibodies by immunoprecipitation of radiolabelled recombinant mouse IA-2. Sera from humans strongly positive for autoantibodies to IA2 and mouse monoclonal antibody-161 to IA-2 served as controls.

As seen in Figure 1, human diabetic sera immunoprecipitated mouse recombinant IA-2. Similarly, mouse monoclonal antibody also immunoprecipitated mouse recombinant IA-2. Pilot studies (Fig. 1) showed that sera from diabetic NOD/Lt mice (kindly provided by Dr. E. H.Leiter, Bar Harbor, Maine, USA) failed to immunoprecipitate mouse IA-2. To further investigate the ability of NOD mouse and BB rat sera to immunoprecipitate mouse recombinant IA-2, a total of 103 NOD mouse sera (13 normal, 61 prediabetic and 29 diabetic) and 102 DP-BB rat sera (12 normal, 12 prediabetic and 78 diabetic) were tested. Antibody to IA-2 was not detected in any of the 205 sera tested.

NOD mice and BB rats have been extensively studied as autoimmune models for human IDDM and have been widely

Corresponding author: Dr. M. S. Lan, Laboratory of Oral Medicine, Building 30, Room 124, NIDR/NIH, 30 Convent Dr. MSC4322, Bethesda, MD 20892-44322, USA

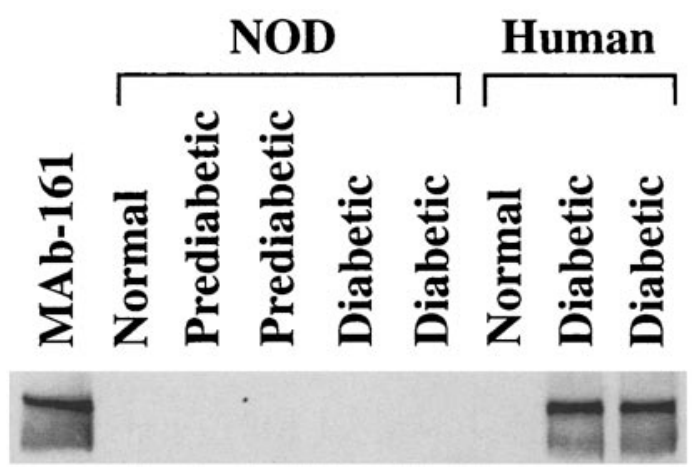

Fig.1. Radioimmunoprecipitation of mouse recombinant IA 2. NOD/Lt mouse and human sera were incubated with mouse recombinant IA-2 expressed in a rabbit reticulocyte system. The precipitates were separated on an $8 \%$ SDS-PAGE gel. Bands with a molecular mass of approximately $106 \mathrm{kDa}$ were precipitated by mouse monoclonal anti-IA-2 antibody- 161 and two human diabetic sera that were shown to react strongly with human IA-2 recombinant protein in a previous study

used in therapeutic trials [6]. In humans, autoantibodies to islet cells [9], insulin [10], and glutamic acid decarboxylase [11] are particularly important predictive markers for the development of IDDM. Some, but not all, of these autoantibodies have also been found in NOD mice and BB rats [12-14]. Their role in the pathogenesis of IDDM, however, remains unclear. The failure reported here to find autoantibodies to recombinant mouse IA-2, by a very sensitive test, points to still another difference in the autoimmune responses of animals and humans with IDDM. This finding, however, does not detract from the usefulness of NOD mice and BB rats in studies involving autoimmune pathogenesis and therapy.

Yours sincerely,

M. G. DeSilva, H.-S. Jun, J.-W. Yoon, A. L. Notkins, M. S. Lan

\section{References}

1. Lan MS, Lu J, Goto Y, Notkins AL (1994) Molecular cloning and identification of a receptor-type protein tyrosine phosphatase, IA-2, from human insulinoma. DNA Cell Biol 13: 505-514

2. Payton MA, Hawkes CJ, Christie MR (1995) Relationship of the 37,000 - and $40,000-\mathrm{M}_{\mathrm{r}}$ tryptic fragments of islet 
antigens in insulin-dependent diabetes to the protein tyrosine phosphatase-like molecule IA-2 (ICA512). J Clin Invest 96: 1506-1511

3. Lu J, Li Q, Xie $\mathrm{H}$ et al. (1996) Identification of a second transmembrane protein tyrosine phosphatase, IA-2 $\beta$, as an autoantigen in insulin-dependent diabetes mellitus: Precursor of the $37 \mathrm{kDa}$ tryptic fragment. Proc Natl Acad Sci USA 93: 2307-2311

4. Notkins AL, Maclaren NK, Wasserfall C, Lan MS (1995) IA-2, a transmembrane protein of the protein tyrosine phosphatase family, is a major autoantigen in IDD. Autoimmunity 21: 49 A118 (Abstract)

5. Leslie RDG, Hawa M, Rowe W et al. (1995) Antibodies to a tyrosine phosphatase-like molecule precede and predict IDDM: an identical twin study. Autoimmunity 21: 60 A230 (Abstract)

6. Rossini AA, Handler ES, Mordes JP, Greiner DL (1995) Animal models of human disease. Human autoimmune diabetes mellitus: lessons from BB rats and NOD mice. Clin Immunol Immunopathol 74: 2-9

7. Lu J, Notkins AL, Lan MS (1994) Isolation, sequence and expression of a novel mouse brain cDNA, mIA-2, and its relatedness to members of the protein tyrosine phosphatase family. Biochem Biophys Res Commun 204: 930936
8. Passini N, Larigan JD, Genovese S, Appella E, Sinigaglia F, Rogge L (1995) The 37/40 kilodalton autoantigen in insulin-dependent diabetes mellitus is the putative tyrosine phosphatase IA-2. Proc Natl Acad Sci USA 92: 9412-9416

9. Bottazzo GF, Florin-Christensen A, Doniach D (1974) Islet-cell antibodies in diabetes mellitus with autoimmune polyendocrine deficiencies. Lancet ii: $1279-1283$

10. Palmer JP, Asplin CM, Clemons P et al. (1983) Insulin antibodies in insulin-dependent diabetics before insulin treatment. Science 222: 1337-1339

11. Baekkeskov S, Landin M, Kristensen JK et al. (1987) Antibodies to a $64,000 \mathrm{Mr}$ human islet cell antigen precede the clinical onset of insulin-dependent diabetes. J Clin Invest 79: 926-934

12. Atkinson MA, Maclaren NK (1988) Autoantibodies in nonobese diabetic mice immunoprecipitate $64,000-\mathrm{Mr}$ islet antigen. Diabetes 37: 1587-1590

13. Baekkeskov S, Dyrberg T, Lernmark A (1984) Autoantibodies to a 64-kilodalton islet cell protein precede the onset of spontaneous diabetes in the BB rat. Science 224: $1348-1350$

14. Markholst H, Klaff LJ, Kloppel G, Lernmark A, Mordes JP, Palmer J (1990) Lack of systematically found insulin autoantibodies in spontaneously diabetic BB rats. Diabetes 39: $720-727$

\section{Mortality of childhood-onset IDDM patients in Estonia}

Dear Sir,

Insulin-dependent diabetes mellitus (IDDM) leads to excess risk of mortality in developed countries even today [1]. Virtually no data are available on the mortality of IDDM patients in eastern Europe apart from a report from former East Germany on insulin-treated patients [2]. We report the mortality among childhood-onset IDDM patients from Estonia which until 1991 was a constituent republic of the former Soviet Union.

Patients were taken from the Estonian population-based childhood-onset IDDM registry which since 1980 has collected information on newly diagnosed cases aged $0-14$ years [3]. Between 1 January 1980 and 31 December 1989340 children were diagnosed with IDDM in Estonia. Registration of cases during 1980-1989 was estimated to be at least $95 \%$ complete using the capture-mark-recapture approach.

The survival status of this cohort was determined as of 1 January 1992. Attending physicians were asked to note the last date when the patient had visited the office or had been hospitalized. Additional information was obtained from currency exchange lists. Currency exchange took place in Estonia in June 1992 and those on the list had to be alive on 1 January 1992. In a minority of cases untraceable by these methods, telephone interviews were conducted and/or the cases traced by mail. Follow-up information was available on 339 cases $(99.7 \%)$. The only untraceable case was censored 1 week after diagnosis as the possibility of death of the patient was excluded. Seven subjects had emigrated and were censored at

Corresponding author: T. Podar, MD, Hospital of Endocrinology, Pikk 64, EE-2400 Tartu, Estonia the date last known to be alive. Since information on death certificates is known to be imprecise [4], the cause of death in each case was determined by careful review of hospital records and interviews with physicians and relatives by one of the investigators (T.P.). Background data on the mortality of the population of Estonia were obtained from the Department of Epidemiology and Biostatistics, Institute of Experimental and Clinical Medicine. Life-table analysis was used for the assessment of the survival of the cohort. Standardized mortality ratios (SMR) were computed using the computer package PersonYears [5]. 95\% confidence intervals (CI) of SMRs were calculated assuming the Poisson distribution.

The mean duration of follow-up was 6.1 years (range 012). The oldest possible attained age was 26 years. During the follow-up $10(2.95 \%)$ individuals died, seven male and three female. The crude mortality rate among the cohort was 425 per 100000 person-years. The 10 -year cumulative mortality of the cohort was high at $6.1 \%$. The overall SMR (all causes) for the age group 0-29 years was 5.01 (95\% CI 2.41-9.22) (Table 1). SMRs for males and females were similar and nonEstonians tended to have a somewhat higher SMR than Estonians $(8.85(95 \%$ CI $1.82-25.84)$ vs 3.50 (95\% CI 1.40 7.21), respectively).

Deaths were most often due to diabetic ketoacidosis, the main killer of the pre-insulin era, which accounted for $50 \%$ of deaths, four in males $(57 \%)$ and one in females (33\%). One male died from diabetic ketoacidosis at the onset of IDDM. One female was found dead in bed which could have been related to an acute diabetic complication but the possibility of suicide could not be excluded. One male and one female died because of cancer and two males in motorvehicle accidents. Careful investigation of the circumstances of the accidents revealed that in neither case was diabetes the cause. No deaths were due to chronic complications of IDDM or cardiovascular disease.

Despite the small size of the cohort and small number of deaths, these data should give an adequate estimate of the 